
\title{
$\angle S$ Research Suare \\ Illuminating Health Aspects for Immigrant Thai Women Living in Swedish Transnational Marriages
}

Weerati Pongthippat ( $\nabla$ weerati.pongthippat@mdh.se )

Mälardalen University

Gunnel Östlund

Mälardalen University

Mehrdad Darvishpour

Mälardalen University

Jureerat Kijsomporn

Ministry of Public Health

Lena-Karin Gustafsson

Mälardalen University

\section{Research Article}

Keywords: critical incident technique, international marriages, migrant health, wellness

Posted Date: October 25th, 2021

DOI: https://doi.org/10.21203/rs.3.rs-923410/v1

License: (c) (i) This work is licensed under a Creative Commons Attribution 4.0 International License. Read Full License 


\section{Abstract}

Background: Based on their migrant status, women experience discrimination, facing major risks including sexual exploitation, trafficking, and violence which all affect health.

This study explores critical health incidents of marriage migration and their consequences experienced by immigrant Thai women in everyday life.

Methods: A qualitative explorative approach with in-depth interviews. 40 immigrant Thai women having or having had a Swedish spouse. Critical incident technique was used to collect and analyse data in combination with content analysis.

Results: The women reported 438 critical health incidents in five main areas: Psychological health dilemmas with consequences such as detrimental insecurity, loss of human value and devastating grief. Sociocultural health dilemmas leading to exploitation, insecurity, feelings of betrayal and rage. Physiological health dilemmas leading to economic strain, emotional strain, and physical pain. Developmental health dilemmas are affected by the process of ageing and facing threatening incidents related to deteriorating health. Spiritual health dilemmas including critical incidents in which the women intensified their dependence on faith and karma.

Discussion: Women in marriage migration face major health dilemmas while adapting to their new country. Healthcare providers should be concerned about migrated women's complex situations, as these affect both health and welfare.

\section{Background}

Immigration is a highly stressful experience that impacts migrant women's health and well-being [1]. The process of marriage migration is often problematic as it includes major health risks e.g., difficulties speaking and understanding a new language, domestic violence due to treats from spouse and continuing economic poverty $[2,3,4]$. Violence has been recognized as a serious public health problem for women and children worldwide [5, 6]. Earlier research confirms that Intimate partner violence (IPV) is deeply linked to poor mental health $[5,7,3]$. Women who abandon their families and children when relocating are also more vulnerable to violence [8].

Several studies at the start of the 2000s showed that acculturative stress can be penetrating and prolonged, increasing the risk of emotional and mental health problems $[9,10,11]$. This is based on the following range of acculturation stressors e.g., culture, language, financial situation while acclimatising to the new country $[2,4]$.

Moreover, migrant women repeatedly carry distress with them from their previous nation or culture to the new one [10], which creates stress, marital instability, and subsequent ill health, confirming that marriage migration affects health and well-being [12]. The incidence of specific types of mental health 
complications is influenced by the migration experience, in terms of bad health conditions experienced before, during and after [13].

Traditionally, Thai women's values, are centred on family responsibilities and how they manage to handle them from the new country, while also being aware of and caring for their own health needs [14]. Marriage migration has also been discussed as a welfare problem based on the marginalised and unequal status these women experience in the new country [15]. Immigrant women are supposed to have equal rights to fulfil their needs of general health, care, and social service in the new country.

Discrimination, economic problems, and partner violence often result in transnational marriages causing increased stress and difficultly in new relationships [16].

The general goal of nursing, particularly regarding health, is to provide patient health promotion while preserving respect for the individual and all human beings [17].

A more direct explorative study is needed to empirically extend knowledge of 'transnational marriage migration', as research concerning coping with immigrant life among these women is rare. Therefore, this study explores critical health incidents of marriage migration and their consequences as experienced by immigrant Thai women in everyday life.

The study has an inductive approach, even if the Neuman System Model (NSM) [18] has inspired our naming of the main health dilemmas e.g., the main areas of critical incidents found in the analysis of the results. The NSM model will be used to further discuss the implications of the results. Betty Neuman [19] argues that the concept of wellness is based on and could be equated to the harmony of the system when it is in a state of "balance" that focuses on (a) physiological, psychological, sociocultural, developmental, and spiritual health variables; (b) showing a systemic holistic approach to the person or patient, in which the individual has (c) a flexible and normal line of resistance, based on (d) the characteristics of the internal, external, and created environments surrounding the person, as well as (e) characteristics of intrapersonal, interpersonal, and extra personal stressors; and ( $f$ ) the basics of possible primary, secondary, and tertiary prevention $[19,20]$.

\section{Methods}

\section{Study design and participants}

A qualitative design was used with semi-structured questions based on critical incident technique (CIT) [21] further described by Fridlund, Henricson and Mårtensson [22]. This methodology has the purpose of categorizing difficult situations which people experience and the consequences of these critical incidents [23]. The sample included 40 immigrant Thai women using the following criteria: (a) born in Thailand and self-identified as Thai, (b) lived in Sweden for at least five years, and (c) currently or previously married/had a relationship with a Swedish man. The socio-demographic characteristics of the participants are presented (Table 1). 


\section{Setting and sample}

The first author asked three Thai cultural associations located in three different sized municipalities in the capital of Sweden to list possible members that might agree to take part in research. Listed women (60) received an invitation letter describing the research project, enquiring about participation, and outlining their right to terminate their voluntary participation in the study at any time. A total of 44 participants replied through the Thai chairpersons who then confirmed the appointment with volunteers (e.g., telephone, letter, or email). Finally, 40 Thai women who were enthusiastic joined the research project, four women rejected participation, and one was forbidden to participate by her partner. Two women felt too anxious and uncomfortable to share experiences and one woman missed the appointment four times.

The semi-structured interview guide was first pilot tested to appraise functionality, with small corrections being made as suggested by Green [24]. The semi-structured interviews were conducted in Thai, Thai and English, or Isan (a local Thai dialect spoken in north eastern Thailand), according to participant preference. The first author is a native speaker of Thai and Isan. The interview started with the question: "How do you deal with everyday life in Sweden?" and the women were encouraged to provide or expand on details based on specific situations. The interviews were audiotaped, ranged from 50 to 90 minutes and transcribed verbatim in Thai by the first author.

\section{Data collection and analysis}

During the first (familiarization) step, the transcribed data was read several times to gain a sense of the whole. This reading included gaining a sense of the range of the women's experiences of critical health incidents as immigrants in their new country. The interviews were read horizontally, referring to individual informants, and vertically, referring to specific answers from the informants. The first author and one coauthor are Thai native speakers, who confirmed the transcripts accurately retained the meaning of the answers. Contextual and complementary information were encountered by the horizontal reading, while the vertical reading was completed to capture common features in the replies. The transcripts were then used throughout the analytical process. In data reduction, the first author noted the identified critical health incidents and consequences. From the initial part of the analysis to the clustering and organising into groups such as the main health dilemmas, during which the critical health incidents and consequences were first extracted from the text, they were given sticky tags, and transferred onto cards extracted from the text. The categorisation of critical health incidents was later discussed in the research team to reach a final classification of main health dilemmas. Validation that the critical health incidents formed part of the interviews' contents was performed by the Thai bilingual author.

\section{Results}

As a part of everyday life in marriage migration, the immigrant Thai women reported 438 critical health incidents which were clustered into psychological, sociocultural, physiological, developmental, and spiritual health dilemmas with related consequences (Table 2). 


\section{Psychological health dilemmas}

The psychological health dilemmas were divided into seven subcategories: emotional abuse by the spouse (66), being overloaded with family responsibilities in both countries (34),

leaving family behind (30), leaving unpaid debts behind (22), excessive gambling and resulting economic debts (6), being thrown out of one's home (11), and being left by a spouse (9).

These critical health incidents included women facing emotional pressure including emotional violence such as being kicked out of their home or being forced to go through with a divorce. These situations contributed to loss of human value due to lack of influence and insecurity connected to survival in the new country. Being left by the spouse caused psychological ill-health both in the short and long term, as not only had love and trust gone, but the women had also been abandoned with no money. This affected their personal and transnational responsibilities. Nonetheless none of the Thai interviewees deliberated returning to Thailand because of the risk of losing face.

"...Losing him who I [we] love is to alter my life forever. He destroyed family when he left us [me and our daughters]. I was losing, I didn't know how I can tell my daughters...I can't tell people, lose face, lose pride [tearful] it looked like I am dying" (C-19).

As the interviewed women described, these critical incidents included the loss of pride and the guilt they experienced of not being able to economically support and be there for their families in Thailand. These additional critical health incidents might also include difficult family relationships in Sweden or in some cases Thailand which caused a lot of worries and psychological strain.

"...I feel I have nowhere to turn and the combination of lack of money, the guilt of leaving my family behind, along with not helping my family is overwhelming" (C-29).

Some women saw no possibility but to risk their money in gambling, in the hope of getting extra money, but excessive gambling resulted in debts. Experiences of emotional violence and exploitation both verbal and non-verbal increased women's loss of self-confidence.

\section{Sociocultural health dilemma}

The women described sociocultural health dilemmas which were identified in five subcategories: continuing transnational duties (34), caring and attention for Swedish stepchildren and Thai children (27), refraining from transnational duties (19), caring for Swedish husbands (18), and betrayed by Thai friends and deceived into human trafficking (8).

The Thai support that some women received from 'friends' in Sweden, who they believed were trustworthy was a critical health incident experienced as being connected to sociocultural health dilemmas. The interviewed women experienced disappointment when they placed too much faith in Thai people's 
support. Some women paid their so-called friends to plan, organize and contact Swedish males who would guarantee marriage and a possible job, e.g., the opportunity of living in Sweden.

"My Thai friend and her Swedish husband introduced me to many Swedish men... they came to see me. I felt awkward and bad, but my Thai friend said, 'it's nature [you need only one Swedish male who helps you to live here]" (C-24).

These new connections were often provided by Thai women and their Western husbands. They could be recognised as human trafficking and gave the women even less security in their new country, those that should be trusted could not be trusted. Rage also accompanied these critical health situations when being betrayed by women from your own country.

The interviewed women also experienced critical health incidents connected to sociocultural health while dealing with their older Swedish husbands who were sick and needed daily care or when caring for Swedish stepchildren and Swedish relatives as these types of family responsibilities were part of Thai marriage migration. Enormous demands from their new family were described when fulfilling family responsibilities. Others talked about how the transnational responsibilities in Thailand from children, family and relatives forced them to seek extra work to earn enough money to send back. Constant work affected the women's health, and they experienced exhaustion, strain, and fatigue. Even if the woman did not provide transnational help, she felt bad because this was expected from her home country.

The interviewed women said that Thai family and relatives assumed that being married to a Swedish man meant being wealthy. When interviewees received accusations from their Thai families and relatives, they were left feeling hurt, upset, sad, embarrassed as if they had let the family down.

\section{Physiological health dilemmas}

In this main area 54 critical health incidents affecting physiological health were identified in five subcategories: environmental accidents (16), domestic work accidents (14), being beaten by the spouse who had excessive drinking (12), employed work accidents (6), and being beaten by the other (6). The physiological health dilemmas sustained by 'accidents' often resulted in the woman giving up work for an extended time and some continued being unable to work altogether.

"...I slipped on the wet floor, hurting my coccyx and my back. The doctor diagnosed a lumbar injury and the resulting pain in my back was terribly painful [...]. I could not work, no money to send to my mother and kids...just lying-in bed [...]" (C-21).

The women described how unpredictable 'accidents' increased the economic strain for them and made their immigrant lives even more difficult. The women were victims of intimate partner violence (IPV) or work overload, both at home and in paid work. A few drank too much alcohol and ended up in accidents and fights. The women kept silence about the causes of these so-called accidents which only increased their bad health situation as well as hindered relevant health treatment. 
"We had problems for many years, constantly arguing. He hit me when he was drunk [...] I did not tell the police or anyone because I am illiterate and I needed his support also I loved him, and I didn't want to lose my family... I was embarrassed, I took sick leave, stayed away from people and the doctor. I hid away and healed myself. I was extremely stressed, unable to sleep..." (C-1).

Some of the women used health care services, but others did not as they felt too ashamed and refrained from showing their physiological injuries even to a nurse or physician. They often resorted to their native upbringing instead and tried to heal themselves with Thai herbs.

\section{Developmental health dilemmas}

The interviewed women described developmental health dilemmas that were divided into four subcategories of critical health incidents: facing the process of becoming older / adapted to ageing (18), having a serious disease (12), caring for the ageing and older husband (10), and facing threatening situations such as no longer being able to handle a wife's duties (4).

Associated to wife's responsibilities, some interviewees also described the monotony of being a caregiver of the older and ageing husband and fear of the Swedish husband dying and being left alone leading to developmental ill-health and detrimental insecurity of the future to come. These interviewed Thai women were precluded from work and pre-existing health problems worsened due to age.

"I am now 59 with diseases [diabetes and hypertension], 25 years living here with basic Swedish language skills and no English. I can't explain to Swedish health professionals when I get sick. Shameful, isn't it? [...]. My Swedish spouse had a stroke, and he is gone [died]. I have no kids and no relatives, so I leave my life with luck and Buddha [voice full of sadness]" (C-38).

The Thai women explained that leaving their older Swedish husbands was not an option because of gratitude and fear of karma in the future or next life. Buddhist belief in karma made their existing life expectancy and transnational responsibilities hard to bear. Marriage life also became complicated by other wives wanting to replace them due to age. Power and strength were lost based on the ageing process and recognising one's ageing, health issues and inability to work due to cancer, heart disease, stroke, hypertension, diabetes mellitus and so on.

"I am unable to read or write so I work as a cleaning lady [...] My Thai son [autistic] and now I have been diagnosed with cancer thinking about what will be happen if something happens to me [...] Can my son survive? Can my son live with his Swedish stepfather? I have these questions around my head every night before I fall asleep" (C-20).

The interviewed women described several critical health incidents identified in the process of becoming older and developing poor health. The most important factor for their developmental health was how to adapt to the process of ageing. The Thai women interviewees all said that they knew when bad luck or bad things happen in their lives in Sweden, it is important to be patient and face those events. 


\section{Spiritual health dilemmas}

The three subcategories of critical health incidents interpreted as the spiritual health dilemmas were: praying for lessening previous bad karma (38), worshiping holy things (11), and talking to a fortune-teller and a monk (7).

Spiritual health dilemmas affected the interviewed women's lives and health when spirituality was experienced as their only salvation from life's difficulties. These interviewees described spiritual and magical resources as giving hope when faced by any negative event in life including bad health of different kinds. Therefore, spirituality was described as their main health resource. These women explained that it was hard to trust people Thai or others. In critical health incidents such as when losing a husband and losing face or when being left by their Swedish spouse and being replaced by another woman, spirituality and faith were what, according to them, was left. This leads to acceptance rather than a changed health situation.

"My husband asked for me for a divorce. I was angry. I had lost everything. I felt suicidal and wanted to kill both my ex and his new girlfriend [...]. I met a monk and fortune-teller who explained that because in a previous life I had hurt them [...] bad karma followed me, I should pray with holy items, then my stress and bad luck would vanish" (C-34).

Some of the interviewed women, often without schooling, interpreted all critical incidents in life, health related or not, to be treatable by spiritual and religious behaviours rather than turning to social or professional health and welfare. These women did not know what they could ask for related to health care and welfare support. This was partly due to poor language skills and being unable to communicate what they required, and partly due to social isolation. One of the interviewed women described how she resorted to spiritual beliefs in times of ill-health and how she understood that her recovery depended on her spiritual behaviour.

Consequently, these spiritual and religious practices were not always accepted by Swedish spouses, and for some of the women their conviction led to relational conflicts when continuing to perform spiritual practices in Sweden. Nevertheless, these women illuminated how spirituality was deeply rooted in their background and in health.

\section{Discussion}

The interviewed women described physiological psychological, sociocultural, developmental, and spiritual health dilemmas experienced in marriage migration. These descriptions contribute to extended knowledge of marriage migration that is transferable, especially in relation to migrating women from Thailand and Asian countries.

Psychological health dilemmas were described such as emotional violence in the family from the spouse or from family members, relatives, and friends or broken relationships of different kinds. The interviewed 
women experienced exploitation both verbal and non- verbal contributing to loss of self-confidence and security. They expressed feelings such as hopelessness, and loss of pride and guilt. Some women tried to release tension with alcohol causing a heavier burden of mental pain. The interviewed women were full of future expectation and hopes. Some took economic risks with their money by gambling, with extreme gambling resulting in debt. According to an earlier study by Duangkumnerd [25], women in marriage migration in Germany had problems with gambling, quarrelling, adultery, and competing with the Thai network in the new country.

Drawing from the NSM $[18,20]$, psychological health dilemmas in immigrant Thai women influenced their security. Women in marriage migration experienced intrapersonal stressors, connected to their experiences of emotional violence, causing guilt and insecurity. Interpersonal stressors, such as financial problems, family responsibilities or difficulties in life (drinking, gambling, etc.), are stress and strain producing that have the possibility of interrupting an individual's systemic ability to create health and wellness. Also, extra-personal stressors while dealing and interacting with people outside your intra and interpersonal systems such as more distant relatives, work colleagues and friends can interrupt the individual's systemic ability to create health and wellness.

Sociocultural health dilemmas included consequences such as increased stress. Being overloaded with responsibilities in both countries and being torn between two cultural realities and demands added to this stress. Owing to transnational responsibilities and roles, most migrant women wanted to provide for their family which had high expectations $[26,14,27]$. The women found transnational responsibilities exhausting and betrayal by their Thai friends in Sweden additionally difficult to handle. Continuing transnational demands made from family and relatives in Thailand that Thai immigrant women are faced with, seriously affected their mental health. The women worked hard to not only support their families in Thailand but to show their success and gain status with their hometown neighbours [25].

Thai women interviewees agreed that they experienced exhaustion, strain, and fatigue due to heavy domestic workload and less time for rest which affected their health. Stressors of different kinds and from different countries seemed to overwhelm the women beyond what one individual can handle and seriously affected the individual's health and systemic balance $[18,20]$. Acculturative stress when continued, increases the risk of mental health problems as shown by previous scholars $[28,10,9,11,2$, 12]. Intrapersonal and interpersonal stressors were related to workload and lack of rest, linked to transnational duties. Additional energy is used up by the system in its state of disorganization. The outcome may be exhaustion, and this affects wellness [20].

The interviewed women's physiological health dilemmas include so called 'accidents' in difficult day-today conditions such as personal, social, and environmental conditions at home, in spare time or at the workplace. The interviewed women experienced that as a Western wife you had to concentrate on earning money ("blinded for anonymity", 2020) rather than taking care of your own health or satisfying the dreams of a loving marital relationship that marriage migration suggests [27,29,]. Physiological health issues could lead to increased stress and emotional illness that required health care services which some 
interviewees accessed. Others would rather consult Thai friends and relatives or treat themselves with Thai herbs for healing physical wounds. This agrees with previous research that immigrant South Asian women usually consult relatives when they make health care decisions [30]. The results showed that the women were embarrassed and humiliated after being beaten by a spouse, or, by being betrayed by their so-called friends. They were unprepared for physiological and psychological health dilemmas being part of marriage migration. This led to illness of different kinds, and not least to emotional strain.

Moreover, quite a lot of critical health incidents could be related to the women's developmental health such as fear of not being able to continue a so-called wife's duties in marriage migration, as well as facing, and acclimatizing to ageing. Western men tend to be in and seek partnerships with women who are about fifteen years younger [31]. This age gap was confirmed by the interviewed women in the present study. Being a caregiver to an older and ageing husband can cause sadness, worries, and grief resulting in detrimental insecurity.

According to the NSM model $[18,19,20]$, Thai Western wives were subject to intrapersonal stressors. These were enhanced by the ageing process which added more insecurity. Being separated from a beloved Swedish spouse, having no offspring, and having no support from family and relatives caused more sadness and stress on Thai women migrants, adding to their interpersonal stressors. While extrapersonal stressors were a psychological distress such as being a caregiver for a Swedish spouse. These directly affect the central core of the individual's energy resources and influence existing stress.

The interviewed women also experienced critical health incidents related to spiritual health dilemmas. Turning to spiritual and religious behaviour were more common in illiterate women, although all interviewees were Buddhists by faith. Our results indicated that worshiping holy things and asking for guidance from a fortune-teller or Buddhist monk are part of the women's health and wellness system. These spiritual and religious practices seemed to be predominantly supportive, giving hope when faced by any negative event. However, these women seldom used health and welfare services. Seeking behavioural health care among Asian immigrants is prevented by social stigma, shame and saving face.

Womankind is at particularly high risk for the evolution of psychiatric diagnoses during their lifetimes [32].

Therefore, in caring sciences and related areas women in marriage migration have spirituality needs that must be included in the knowledge and understandings of their health and wellness. The interviewed women provided structure and guidance in critical health incidents through spirituality. Not only praying but also invoking and asking for good things; spiritual requests to give new hope that can connect to traditions and belief.

Research has also shown that immigrant women often rely on religious teaching and beliefs along with consulting others who have similar beliefs instead of seeking modern medical treatment $[33,34,35]$. 
In the NSM model, the characteristics of the internal, external, and created environments belong to the surroundings of the immigrant women. But, according to Neuman [19], intrapersonal stressors come from the woman's individual characteristics and the way previously described experienced critical health incidents are handled. Following the theoretical concept of the NSM [20], every person is born with a spiritual energy force and the body has the potential to be sustained through the positive use of this spiritual energy. Thai women's so-called line of resistance (e.g., the responsibilities that Tai women are born with) could be understood as the possibility to stabilize the individual's core system depending on the individual's degree of reactions and flexibility as well as their health dilemmas.

Sociocultural demands also affect the individual's adaptation interpretations/ reactions to symptoms and illness, ability to seek help, emotional expression and communication styles, as well as interactions between patients, families, and health care providers [36]. Thai professional health workers should consider what Thai women need to know before migrating to Sweden. NSM guides how holistic nursing practice could be managed [37]. The interviewed women that had immigrated to Sweden dreamt of better and wealthier lives. This can be described as a core of energy and line of resistance [20] that could be maintained and supported to survive in a new country.

The existing study points to the need, again, that the primary concern of Thai family and relatives in Thailand is the need for money. The reality for Thai women in marriage migration is that their choices to move to a new country dramatically influenced their lives and health. Experienced health dilemmas based on critical health incidents (e.g., accidents at or from work, accidents from domestic housework, environmental accidents, or intimate partner violence, etc) seem to have major influences on lives. These marriage migration realities were not expected by the migrating women. No women were informed by health and welfare authorities in Thailand or by the Embassy in Sweden about possible marriage migration health dilemmas or problems, or who to turn to in case of emergency. The silence of authorities contributes to women's broken dreams of becoming a wealthy Western wife [38, 3], and this lack of public health information increasingly causes further health and welfare problems [15].

\section{Methodological Considerations/ Strength And Limitations}

Critical incident methodology has been used in a broad sense to include the women's descriptions of critical health incidents affecting their life in Sweden. Flanagan's [21] critical incident methodology had the intention of analysing more specific situations. In the present study the women's narratives usually included a chain of situations that were interwoven contributing to poor health and categorized in socalled main health dilemmas. The numbers of critical incidents were more than the 100 required for saturation in CIT studies [21, 39, 40,23]. The sample of interviewees varied in relation to age, educational level, years of immigration, etc. The interviewer as a mental health nurse educator and a native speaker in Thai and Isan (a local Thai dialect spoken in north eastern Thailand) has, together with the interviewees, created a richness of unusual data. 


\section{Conclusion}

From a caring and health promotion perspective, health and welfare professionals in both Sweden and Thailand need to be aware of and learn more about providing healthcare for marriage migrants. Health dilemmas are based on critical health incidents such as environmental stressors from different countries such as marriage migrant experiences that affect women's psychological, sociocultural, physiological, developmental, and spiritual health.

\section{Declarations}

\section{Acknowledgements}

The authors would like to acknowledge the support from the Thai Cultural association in Sweden for assistance in the identification of possible study participants. Our appreciation goes to all those who supported this study.

\section{Author's contributions}

All the authors were actively involved in the article in different ways and approved the final version for publication.

Weerati Pongthippat ${ }^{1,2}$ conducted all interviews and made substantial contributions to this work. She transcribed the texts from Thai into English and did the preliminary interpretation of the data. As the first author, she prepared the manuscript before and after each revision by the co-authors.

Mehrdad Darvishpour ${ }^{1}$ contributed knowledge in the research of transnational marriages among immigrants. He agrees to be accountable for all aspects of the research process and to ensure that all the research was correctly investigated. His final approval has been given for the final version of the manuscript.

Jureerat Kijsomporn ${ }^{3}$ rechecked the bilingual analysis of the submitted data along with the preliminary results. She also provided perspectives on Thai culture. She agreed to be responsible for all aspects of the data analysis and to ensure that the transcriptions were correctly handled. She has given her final approval for the final version of the manuscript. Gunnel Östlund ${ }^{1}$ made substantial contributions to the development of the Critical Incident Technique (CIT), and the Neuman System Model, as well as the design and formulation of the results for the manuscript. She supervised and supported the research process and gave her final approval for the final version of the manuscript.

Lena-Karin Gustafsson ${ }^{1}$ made substantial contributions to the concept of the Neuman System Model and to the design of the work as well as formulation of the results for the manuscript. She supported and supervised the research process.

\section{Funding}


This paper is part of a PhD project funded by the Mälardalen University in Sweden, and was funded in cooperation with Boromarajonani College of Nursing, Udon Thani. The college is part of the Praboromarajchanok Institute for Health Workforce Development.

\section{Availability of data and materials}

The dataset analysis for this current study can be made available upon request to the author (WP).

\section{Ethical approval and consent to participate}

To ensure each participant understood the purpose of the study and provided well-informed consent to participate, the author explained its purpose and procedures as well as provided written consent forms in the native, Thai language of the participants. The identity of each participant was protected throughout the research process and in the study's final report. The study's author informed all participants of their right to withdraw at any time. The study's use of human data was conducted in accordance with the Declaration of Helsinki and was approved by the Swedish National Ethical Vetting Board (number 2016/542).

\section{Consent for publication}

Not applicable.

\section{Competing interests}

The authors declare that this study has no competing interests.

\section{Author details}

${ }^{1}$ School of Health, Care and Social Welfare, Mälardalen University, Eskilstuna, Sweden; ${ }^{2}$ Mental Health and Psychiatric Nursing Department, Boromarajonani College of Nursing Udon Thani, Udon Thani, Thailand;

${ }^{3}$ Praboromrajchanok Institute for Health Workforce Development, Ministry of Public Health, Nonthaburi, Thailand.

\section{References}

1. Yakushko O, Chronister MK. Immigrant Women and Counseling: The Invisible Others. Journal of Counseling \& Development 2005; 83: 292-298. https://doi.org/10.1002/j.1556-6678.2005.tb00346.x

2. Maydell-Stevens E, Masgoret A-M, Ward T. Problems of psychological and sociocultural adaptation among Russian speaking immigrants in New Zealand. Social policy journal of New Zealand 2007; 30: 178-198. http://hdl.handle.net/10536/DRO/DU:30034195

3. "blinded for anonymity"; 2018 
4. Tschirhart N, Diaz E, Ottersen T. Accessing public healthcare in Oslo, Norway: the experiences of Thai immigrant masseuses. BMC Health Services Research 2019a; 19: 1-10.

https://doi.org/10.1186/s12913-019-4560-9

5. Ellsberg M, Jansen AF, Heise L, Watts HC, García-Moreno C. Intimate partner violence and women's physical and mental health in the WHO multi- country study on women's health and domestic violence: an observational study. The Lancet 2008; 371: 1165-1172. https://doi.org/10.1016/S01406736(08)60522-X.

6. García -Moreno C, Jansen HA, Ellsberg M, Heise L, Watts $\mathrm{CH}$. Prevalence of intimate partner violence: Findings from the WHO Multi-Country: Study on Women's Health and Domestic Violence against Women Study Team. The Lancet 2006; 368, 1260-1269. https://doi.org/10.1016/S01406736(06)69523-8

7. Fernbrant C, Emmelin M, Essén B, Östergren P-O, Graae C-E. Intimate partner violence and poor mental health among Thai women residing in Sweden. Glob Health Action 2014; 7: 1-12. https://doi.org/10.3402/gha.v7.24991

8. Patel P, Handa R., Anitha S, Jahangir S. Emerging issues for international family law: Part 3: Transnational marriage abandonment and the dowry question. Family Law Journal 2016; 46: 14431449. http://onlineservices.jordanpublishing.co.uk/web/p...

9. Crockett JK, Iturbide IM, Torres Stone AR, Mc Ginley M, Raffaelli M, Carlo.G. Acculturative stress, social support, and coping: relations to psychological adjustment among Mexican American college students. Culture Divers Ethnic Minor Psychol 2007; 13: 347-355. https://doi.org/10.1037/10999809.13.4.347

10. Bhugra D. Migration, distress and cultural identity. British Medical Bulletin 2004; 69.: 129-141. https://doi.org/10.1093/bmb/ldh007

11. Gayle V, Boyle P, Flowerdew R, Cullis A. Exploring the relationship between family migration and social stratification through the investigation of women's labour market experiences in contemporary Britain. International Journal of Sociology and Social Policy 2008; 28: 293-303. https://doi.org/10.1108/01443330810890709

12. Tschirhart N, Straiton M, Ottersen T, Winkler, A. Living like I am in Thailand: Stress and coping strategies among Thai migrant masseuses in Oslo, Norway. BMC Women's Health 2019b; 19: 1-11. https://doi.org/10.1186/s12905-019-0836-9

13. Kirmayer LJ, Narasiah L, Munoz M, Rashid M, Ryder AG, Guzder J, et al. Common mental health problems in immigrants and refugees: general approach in primary care. CMAJ 2011; 183: E959E967. https://doi.org/10.1503/cmaj.090292

14. "blinded for anonymity", 2020

15. Hedman H, Nygren L, Fahlgren S. Thai-Swedish Couples in the Swedish Daily Press-Discursive Constitutions of "the Other". NORA - Nordic Journal of Feminist and Gender Research 2009; 17: 3447. http://dx.doi.org/10.1080/08038740802690677 
16. Ekblad S, Kastrup CM. Current research in transcultural psychiatry in the Nordic countries. Transcultural Psychiatry 2013; 50: 841-857. http://dx.doi.org/10.1177/1363461513511181

17. World Health Organization. World report on violence and health. 2002 Edited by GE Krug, LL Dahlberg A Mercy, ABA. Zwi, R Lozano R. Retrieved 9 Aug 2021 from http://citeseerx.ist.psu.edu/viewdoc/summary?doi=10.1.1.649.2297

18. Neuman BM. Health as a Continuum Based on the Neuman Systems Model. Nursing Science Quarterly 1989; 3: 129-35. https://doi.org/10.1177/089431849000300308

19. Neuman BM. The Neuman Systems Model in Research and Practice. Nursing Science Quarterly 1995; 9: 67-70. https://doi.org/10.1177/089431849600900207

20. Neuman BM. Neuman Systems Model. 2002 In: B Neuman, J Fawcett (eds) The Neuman Systems Model. 4th ed. (pp. 3-33) Upper Saddle River: Prentice Hall.

21. Flanagan JC. The critical incident technique. Psychological Bulletin 1954; 51: 327-358. https://doi.org/10.1037/h0061470

22. Fridlund $\mathrm{B}$, Henricson $\mathrm{M}$, Mårtensson J. Critical Incident Technique applied in nursing and healthcare sciences. Nursing Health Care 2017; 3: 1-5. http://dx.doi.org/10.15226/2471-6529/3/1/00125

23. Woolsey LK. The critical incident technique: an innovative qualitative method of research. Canadian Journal of Counselling 1986; 20: 242-254.

24. Green P. A rigorous journey into phenomenography: From a naturalistic inquirer viewpoint. In J Bowden, P Green (Eds.) 2005 Doing developmental phenomenography (pp. 32-46). Melbourne: RMIT University Press.

25. Duangkumnerd V. The Intermarriage of Thai Women in Germany. A Dissertation Submitted in Partial Fulfillment of the Requirements for the Degree of Doctor of Philosophy Population and Development School of Applied Statistics National Institute of Development Administration 2009. Retrieved 28 February 2021 from http://libdcms.nida.ac.th/thesis6/2009/b162504.pdf

26. Lundberg CP. Cultural Care of Thai Immigrants in Uppsala: A Study of Transcultural Nursing in Sweden. Journal of Transcultural Nursing 2000; 11: 274-280. https://doi.org/10.1177/104365960001100405

27. Suksomboon S. Remittance and social remittance: Their impact on livelihoods of Thai women in the Netherlands and non-migrants in Thailand. Gender, Technology and Development 2008; 12: 461482. https://doi.org/10.1177/097185240901200309

28. Aroian KJ. A model of psychological adaptation to immigration and resettlement. Nursing Research 1990; 39: 5-10. https://doi.org/10.1097/00006199-00002

29. Sunanta S, Angeles CA. From rural life to transnational wife: Agrarian transition, gender mobility, and intimate globalisation in transnational marriages in northeast Thailand. Gender, Place \& Culture 2013; 20: 699-717. https://doi.org/10.1080/0966369X.2012.709827.

30. Grewal S, Bottorff LJ, Hilton B. The Influence of Family on Immigrant South Asian Women's Health. Journal of Family Nurs 2005; 11: 242-63. https://doi.org/10.1177/1074840705278622 
31. Constable, N. "Introduction: Cross-Border Marriages, Gendered Mobility, and Global Hypergamy." In Cross-Border Marriages. Gender and Mobility in Transnational Asia, 2005 ed N, Constable, (1-16). Philadelphia: University of Pennsylvania Press.

32. Kramer JE, Kwong K, Lee E, Chung H. Cultural factors influencing the mental health of Asian Americans. West J Med 2002; 176: 227-231.

33. Donnelly TT, Hwang JJ, Este D, Ewashen C, Adair C, Clinton M. If I Was Going to Kill Myself, I Wouldn't Be Calling You. I am Asking for Help: Challenges Influencing Immigrant and Refugee Women's Mental Health. Issues in Mental Health Nursing 2011; 32: 279290. http://dx.doi.org/10.3109/01612840.2010.550383

34. Delara M. Social Determinants of Immigrant Women's Mental Health. Advances in Public Health 2016; 1-11. http://dx.doi.org/10.1155/2016/9730162

35. Cabaço S, Caldeira S, Vieira M, Rodgers B. Spiritual Coping: A Focus of New Nursing Diagnoses. International Journal of Nursing Knowledge 2017; 29: 156-164. https://doi.org/10.1111/20473095.12171

36. Helman C. Culture, health, and illness. 5th ed London (UK): Hodder Arnold, 2007.

37. Lowry LW. A Qualitative Descriptive Study of Spirituality Guided by the Neuman Systems Model. Nursing Science Quarterly 2012; 25: 356-361. https://doi.org/10.1177/0894318412457052

38. Plambech S. "Managing migration - risks and remittances amongmigrant Thai women" 2007, available at: www.academia.edu/29376439/Managing_Migration_risks_and_ Remittancesamong_Migrant_Thai_Women (accessed 24 December 2018).

39. Svensson A, Fridlund B. Experiences of and actions towards worries among ambulance nurses in their professional life: A critical incident study. International Emergency Nursing 2008; 16: 35-42. https://doi.org/10.1016/j.ienj.2007.10.002

40. Vasileiou K, Barnett J, Thorpe S, Young T. Characterising and justifying sample size sufficiency in interview-based studies: systematic analysis of qualitative health research over a 15-year period. BMC Medical Research Methodology 2018; 18:-18. https://doi.org/10.1186/s12874-018-0594-7

\section{Tables}

Due to technical limitations, table 1 is only available as a download in the Supplemental Files section.

Table 2 The main health dilemmas based on subcategories of critical health incidents and their consequences from interviews with 40 Thai immigrant women in Sweden, 2016. 


\section{Main health} dilemmas

Psychological Emotional abuse by the spouse (66) health

(178 critical health incidents)

\section{Critical health incidents} in both countries (34)
Being overloaded with family responsibilities

Leaving family behind (30)

Leaving unpaid debts behind (22)

Excessive gambling and resulting economic debts (6)

Being thrown out of one's home (11)

Being left by the spouse (9)
Shame, guilty and self-blame

Devastating grief

\section{Consequences}

Losing human value Irreversibly hurt

Exhausted by conflicting needs

Emotional strain

Frustration, and anxiety

Economic debts

Detrimental insecurity

Losing human value Devastating grief
Sociocultural health

(106 critical health incidents)
Continuing transnational duties (34)

Caring and attention for Swedish

stepchildren and Thai children (27)

Refraining from transnational duties (19)

Caring for Swedish husbands (18)

Betrayed by Thai friends and deceived into human trafficking (8)
Stressed, worried and exhausted

Fatigue

Feeling indignation and disgusting

Fatigue

Exploitation, insecurity,

feelings of betrayal and rage

Unable to carry on working

Economic strain

Emotional strain

Physical pain

Employed work accidents (6)

Being beaten by others (6)

Developmental health
Facing the process of becoming older / adapted to ageing (18)
Deteriorating health, Weak by being elderly 


\begin{tabular}{|c|c|c|}
\hline \multirow{4}{*}{$\begin{array}{l}\text { (44 critical } \\
\text { health } \\
\text { incidents) }\end{array}$} & Having a serious disease (12) & Poor health conditions \\
\hline & \multirow[t]{2}{*}{ Caring for the ageing and older husband (10) } & Detrimental insecurity \\
\hline & & Emotional strain \\
\hline & $\begin{array}{l}\text { Facing threatening situations as no longer } \\
\text { being able to handle a wife's duties (4) }\end{array}$ & $\begin{array}{l}\text { Marriage life affects menopause } \\
\text { and being a proper woman }\end{array}$ \\
\hline $\begin{array}{l}\text { Spiritual } \\
\text { health }\end{array}$ & $\begin{array}{l}\text { Praying for lessening previous bad karma } \\
\text { (38) }\end{array}$ & Dependence on faith and karma \\
\hline \multirow{2}{*}{$\begin{array}{l}\text { (56 critical } \\
\text { health } \\
\text { incidents) }\end{array}$} & Worshipping and holy things (11) & \multirow{2}{*}{$\begin{array}{l}\text { Extending spiritual beliefs, trust } \\
\text { and faith }\end{array}$} \\
\hline & Talking to a fortune-teller and a monk (7) & \\
\hline
\end{tabular}

\section{Supplementary Files}

This is a list of supplementary files associated with this preprint. Click to download.

- Table1.jpg

- Appendixllluminatingwpt.docx 